\title{
İskenderun Körfezi Deniz Suyunun Eser Element Düzeylerinin Araştırılması
}

\author{
Sezer GÖYCINCIK ${ }^{1 *}$, Hatice DANAHALİLOĞLU1 ${ }^{1}$, H. Bekir KARAYİĞİT ${ }^{1}$ \\ ${ }^{1}$ Mustafa Kemal Üniversitesi, Fen Edebiyat Fakültesi, Kimya Bölümü, Antakya, Hatay, TÜRKIYE
}

Geliş Tarihi: 08.05 .2018

"Sorumlu Yazar: sezersav@gmail.com.tr

Kabul Tarihi: 25.07 .2018

\section{$\ddot{\mathbf{O z}}$}

Bu çalışmada İskenderun Körfezi deniz suyu eser element yönünden araştırılarak bu elementlerin belirli periyotlarla değişimleri incelenmiş̧ir. Kirlilik ölçümleri için dört ayrı istasyon belirlenmiştir. Kasım 2014 ve Mart 2015 tarihleri arasında beş ay boyunca 15 günlük periyotlarla 40 adet deniz suyu numunesi toplanmıştır. Bu numunelerin $\mathrm{pH}$, iletkenlik değerleri ile bor, alüminyum, krom, demir, nikel, bakır, arsenik ve selenyum (B, $\mathrm{Al}, \mathrm{Cr}, \mathrm{Fe}, \mathrm{Ni}, \mathrm{Cu}, \mathrm{As}$ ve $\mathrm{Se}$ ) konsantrasyonları ölçülmüştür. Ortalama pH değeri 8,04 olarak belirlenmiştir. Ortalama iletkenlik değeri $103430 \mu \mathrm{S} / \mathrm{cm}$ olarak belirlenmiştir. Eser element analizi ICP-MS cihazı ile yapılmıştır. Ortalama eser element konsantrasyonları; B: 6,559; Al: 0,666; Cr: 0,243; Fe: 7,142; Ni: 0,094; Cu: 0,364; As: 0,055 ve Se: 0,275 ppm olarak bulunmuştur. Analiz sonuçlarına bakıldığında $\mathrm{B}, \mathrm{Al}, \mathrm{Cr}, \mathrm{Fe}, \mathrm{Cu}$ ve Se elementlerinin konsantrasyonlarının sınır değerlerin üzerinde olduğu bulunmuştur. Ni ve As elementlerinin konsantrasyonlarının sınır değerlerin altında olduğu bulunmuş̧tur.

Anahtar Kelimeler: İskenderun Körfezi, Eser element, ICP-MS, Deniz kirliliği.

\section{Research of Trace Element Levels of Sea Water in İskenderun Bay}

\begin{abstract}
In this study, İskenderun Bay sea water was investigated in terms of trace elements and the changes of these elements with were periodically investigated. Four separate stations were identified for pollution measurements. Between November 2014 and March 2015, 40 sea water samples were collected as 15 days periods during five months. pH, conductivity values and boron, aluminium, chromium, iron, nickel, copper, arsenic and selenium $(\mathrm{B}, \mathrm{Al}, \mathrm{Cr}, \mathrm{Fe}, \mathrm{Ni}, \mathrm{Cu}$, As and $\mathrm{Se}$ ) concentrations of these samples were measured. The mean $\mathrm{pH}$ value was determined as 8.04 . The mean conductivity value was determined as $103430 \mu \mathrm{S} / \mathrm{cm}$. Trace element analysis was done by ICP-MS device. Mean trace element concentrations were determined as B: 6.559; Al: 0.666; Cr: 0.243; Fe: 7.142; Ni: 0.094; Cu: 0.364; As: 0.055 and Se: $0.275 \mathrm{ppm}$. According to the analysis results, the concentrations of $\mathrm{B}, \mathrm{Al}, \mathrm{Cr}, \mathrm{Fe}, \mathrm{Cu}$ and $\mathrm{Se}$ elements were found above the limit values. The concentrations of $\mathrm{Ni}$ and As elements were found below the limit values.
\end{abstract}

Keywords: İskenderun Bay, Trace element, ICP-MS, Marine pollution. 


\section{Giriş}

Günümüzde dünya nüfusunda aşırı bir artış ve yoğun endüstriyel gelişim gözlenmektedir. $\mathrm{Bu}$ görülen hızlı büyüme, fabrikalaşma ve nüfus artışı giderek daha büyük boyutlara ulaşan çevre kirlenmesi sorununu da beraberinde getirmektedir. Yoğun nüfusa sahip olan deniz kıyılarında eksik planlanmış atık su deşarjları, petrol rafinerileri, termik santraller gibi endüstri kuruluşlarında bulunan eski teknolojili deşarj sistemleri, ara malzeme olarak kullanılan kimyasallar, boyalar, dezenfektanlar, ilaçlar ve diğer pek çok imalat sanayi yan ürünleri denizler için önemli kirlilik kaynaklarıdır. Bu maddeler, dikkatli kullanılmadıkları ve gerekli denetimleri yapılmadı̆̆ı takdirde denizlerde önemli derecelerde kirlenmeye sebep olabilmektedirler. Buna ek olarak gemi kazaları ve petrol tesislerindeki sızıntılar da bu ortamlardaki kirlenme sebepleridir. Son yıllarda çoğu ülke kıyı bölgelerinin kirliliğe karşı korunmasına artan bir duyarlılık göstermektedir ve bu alanda yapılan araştırmaların sayısı günden güne çoğalmaktadır. Denizler çeşitli sebeplerden dolayı kirliliğe maruz kalmaktadır. Özellikle kıyı bölgelerinde, sanayi tesislerinin artması, yapay gübre, deterjan, pestisit ve fosil yakıt kullanımına bağlı olarak ağır metal konsantrasyonları hızla artmaktadır (Topçuoğlu, 2005).

Deniz suyunda istenmeyen bazı ağır metaller dipte birikerek denizi kirletmektedir. Biriken ağır metaller doğal veya yapay yollarla denize taşınmaktadır. Doğal taşınım nehirlerden ya da atmosferden kaynaklanabilmektedir. Yapay taşınım ise madenciliğin ve sanayinin gelişmesi, fosil yakıtların aşırı kullanımı gibi sebeplerden dolayı gerçekleşmektedir. Özellikle V, Ni, Mo ve Hg bakımından zengin olan fosil yakıtların fazla kullanılmasından dolayı, atmosferden denize birçok ağır metal girmektedir (Topçuoğlu, 2005).

Üzerinde çalışmalar yapılan konuların en önemlilerinden birisi de çevre kirliliğidir (Censi ve ark., 2006; Hamed ve Emara, 2006; Ergül ve ark., 2013). Kirlilik çok farklı alanlarda oluşabilir ancak herhangi bir alanda meydana gelen kirlilik dolaylı veya doğrudan diğer bölgeleri de etkisi altına almaktadır. Genellikle çevre kirliliği, hava, su ve toprakta oluşmaktadır. Canlı hayatında çok önemli yer tutan bu üç unsuru etkileyen kirlilik doğal dengede bozulmalara ve canlı yaşamında olumsuzluklara yol açmaktadır. Hava, toprak ve su arasında kurulmuş doğal dengeden dolayı birisine etki eden negatif etki diğerlerine de dolaylı yoldan etki etmektedir (Lijklema, 1993).

Çevresel problemler arasında en önemli konulardan birisi olan su kirliliği, hem insanlar tarafından oluşturulan yapay hem de doğal sulu ortamlarda önemli problemlere yol açar. Üstelik yüzey sularının kalitesi genellikle endüstri merkezleri ve nüfus artışıyla olumsuz yönde etkilenmektedir. Bununla birlikte bölgelerin özellikleri spesifik olarak farklılıklar gösterebilir (Buckley ve ark., 1995; Pertsemli ve Voutsa, 2007 ). 
Toprak ile havadaki kirlilik kaynakları da su ortamına geçerek su kirliliğine sebep olur. Çünkü toprak ve havadaki kirlilik kaynakları bulundukları alanda kalmaz, yağmur ve sel gibi yollarla yer üstü ve yer altı sularına karışarak kirliliğe neden olur (Karadere, 1997; Beğenirbeş, 2002).

Günümüzde kimyasal bir kirlilik olarak kabul edilen ağır metal kirliliği çeşitli kaynaklardan ortaya çıkabilmeleri, çevre koşullarına dayanıklı olmaları ve kolaylıkla besin zincirine geçerek canlılarda artan yoğunluklarda birikebilmeleri nedeniyle diğer kimyasal kirleticiler arasında ilk sırayı tutmaktadır (Uzunoğlu, 1999).

Akdeniz'in farklı bölgelerinde yüksek oranlarda pek çok eser metalin doğal ya da insan kaynaklı sebeplerle bu ekosisteme girdiği pek çok araştırıcı tarafından rapor edilmiştir. Bu yüzden, Akdeniz ekosistemi için en önemli tehditlerden birisinin metal kirliliği olduğu önemle vurgulanmaktadır (Cubadda ve ark., 2001). Ayrıca farklı şekillerde denizlere taşınan eser elementlerin derişim değerleri, olması gerekenden fazla olduğunda denizde yaşayan canlıların biyolojik aktivitelerine olumsuz bir şekilde etki etmektedir (Uzunoğlu, 1999).

İskenderun Körfezi; çevresinde yoğun sanayi kuruluşları olan, coğrafi konumu ve akıntılar nedeniyle daha uzak bölgelerdeki atık sularla da kirlenmeye açık bir bölge özelliği göstermektedir (Anonim, 2004).

$\mathrm{Bu}$ çalışmada endüstriyel kirliliklere açık olan İskenderun Körfezi’nden 4 ayrı bölgeden 15 günlük periyotlar halinde alınan deniz suyu numunelerinin içerdiği 8 eser elementin $(\mathrm{B}, \mathrm{Al}, \mathrm{Cr}, \mathrm{Fe}$, $\mathrm{Ni}, \mathrm{Cu}, \mathrm{As}, \mathrm{Se})$ konsantrasyonu ICP-MS cihazı ile tespit edilmiştir. Ayrıca numunelerin pH ve iletkenlik değerleri de ölçülmüştür. Elde edilen bulgular aylar ve istasyonlar bazında karşılaştırılmıştır. Böylelikle İskenderun Körfezi’ndeki eser element varlığının hangi boyutlarda olduğu belirlenmeye çalışılmıştır.

\section{Materyal ve Metot}

\section{1. İstasyonların Tespiti}

Endüstriyel kuruluşların sebep olduğu bu kirliliği araştırmak üzere dört ayrı istasyon oluşturuldu. Birinci örnekleme noktası Payas (P)istasyonu İsdemir'in 2 km. kuzeyinde kirletici vasfı yüksek elektrikli ark ocaklı tesislerin, entegre demir çelik tesislerinin, haddehane ve dökümhanelerin aynı zamanda yerleşim yerlerinin yer aldığı Payas ilçe merkezi sahili Örnekleme bölgesinin koordinatlar1: $36^{\circ} 45^{\prime} 43.9^{\prime \prime} \mathrm{N} 36^{\circ} 11^{\prime} 58.0^{\prime \prime} \mathrm{E}$

İkinci örnekleme noktası İsdemir (İ) istasyonu şehrin $20 \mathrm{~km}$. kuzeyinde sanayi kuruluşlarının yoğun olduğu İsdemir civarında bir bölgedir. Örnekleme bölgesinin koordinatları: 3640'30.6"N $36^{\circ} 12^{\prime} 38.2^{\prime \prime} \mathrm{E}$ 
Üçüncü örnekleme noktası Merkez (M) istasyonu nüfus yoğunluğunun fazla olduğu İskenderun kent merkezi sahilidir. Koordinatları: $36^{\circ} 35^{\prime} 31.3^{\prime \prime} \mathrm{N} 36^{\circ} 10^{\prime} 29.4^{\prime \prime} \mathrm{E}$

Dördüncü örnekleme noktası Karaağaç (K)istasyonu şehrin $10 \mathrm{~km}$. güneyinde yer alan Karaağaç Mahallesi sahilinde oluşturuldu Koordinatları: 36³4'49.1"N 3608'03.7"E

İstasyonların yerleri Şekil 1' de gösterilmiştir.

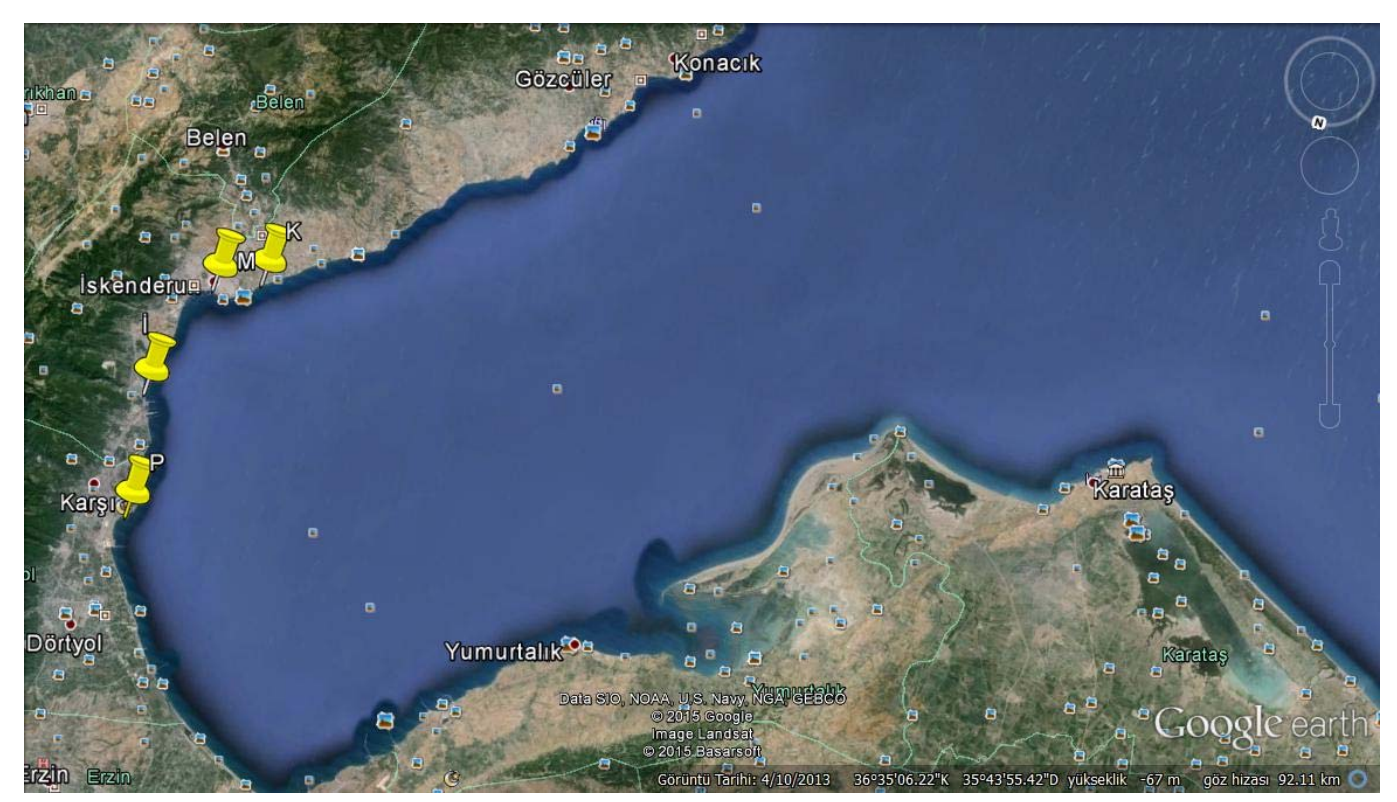

Şekil 1. Örnekleme İstasyonları

\subsection{Numunelerin Alınması}

Örneklemeler 2014 Kasım ayında başlayarak 2015 Mart ayının sonuna kadar kesintisiz bir şekilde 15 günlük periyotlarla sürdürülmüş ve 40 adet numune alınmıştır. Her ayın ortasında ve sonunda her bir istasyondan kıyıdan deniz yüzeyinden polietilen şişeler daldırılarak örneklemeler gerçekleştirilmiştir. Numuneler, alınan polietilen şişeler içerisinde muhafaza edilmiştir. Şişeler bir gece öncesinden seyreltik nitrik asitle yıkandı ve üç defa saf su ile çalkalanarak hazır edilmiştir. Numuneler, alındıktan sonra aynı gün laboratuvar ortamına getirilmiştir. pH ve iletkenliklerine bakıldıktan sonra deniz suyu örneği adi filtre kağıdı ile süzülerek \% 65' lik $\mathrm{HNO}_{3}$ ile asitlendirilmiş $+4{ }^{0} \mathrm{C}$ 'de muhafaza edilmiştir.

Numunelerdeki eser element konsantrasyonları Mersin Üniversitesi İleri Teknoloji, Eğitim ve Araştırma Merkezi (MEİTAM) da Agilent marka 7500 CE Octopole Reaction System model İndüktif Eşleşmiş Plazma Kütle Spektrometresi (ICP-MS) ile ölçülmüştür. 


\section{Bulgular ve Tartışma}

Bu çalışmada İskenderun Körfezi’nin kirliliğine neden olabilecek bazı faktörler incelenmiştir. Her bir numunede körfezin kirlenmesine neden olan sekiz tane eser elementin analizi yapılmıştır. Ayrıca körfezin çeşitli özellikleri dikkate alınarak dört farklı istasyon seçilmiştir. Her bir istasyondan farklı zaman dilimlerinde (Kasım-Aralık-Ocak-Şubat-Mart) kıyıdan deniz yüzeyinden deniz suyu numuneleri alınmıştır. Bu numunelerin pH ve iletkenlik ile Bor, Alüminyum, Krom, Demir, Nikel, Bakır, Arsenik ve Selenyum eser elementlerinin (B, Al, Cr, Fe, Ni, Cu, As ve Se) konsantrasyonları ölçülmüştür. Deniz suyu numunelerindeki eser element konsantrasyonu ICP-MS cihazı ile belirlenmiştir. Her numune üç paralelli analiz edilmiştir.

Tablo 1'de analiz sonucu elde edilen $\mathrm{pH}$ değerleri görülmektedir.

Tablo 1. Analiz sonucu elde edilen $\mathrm{pH}$ değerleri ve standart sapmaları

\begin{tabular}{llllll}
\hline İstasyonlar & Kasım & Aralık & Ocak & Şubat & Mart \\
\hline P İstasyonu & $7,530 \pm 0,028$ & $7,735 \pm 0,092$ & $8,435 \pm 0,049$ & $8,290 \pm 0,057$ & $8,110 \pm 0,014$ \\
I İstasyonu & $7,565 \pm 0,035$ & $7,735 \pm 0,106$ & $8,370 \pm 0,014$ & $8,215 \pm 0,035$ & $7,935 \pm 0,304$ \\
M İstasyonu & $7,710 \pm 0,048$ & $7,835 \pm 0,177$ & $8,395 \pm 0,078$ & $8,330 \pm 0,038$ & $8,110 \pm 0,127$ \\
K İstasyonu & $7,680 \pm 0,021$ & $7,765 \pm 0,106$ & $8,430 \pm 0,042$ & $8,350 \pm 0,062$ & $8,330 \pm 0,025$ \\
\hline
\end{tabular}

Tablo 2'de analiz sonucu elde edilen iletkenlik değerleri $(\mu \mathrm{S} / \mathrm{cm})$ görülmektedir.

Tablo 2. Analiz sonucu elde edilen iletkenlik değerleri ve standart sapmaları

\begin{tabular}{lccccc}
\hline İstasyonlar & Kasım & Aralı & Ocak & Şubat & Mart \\
\hline P İstasyonu & $52850 \pm 1940$ & $115900 \pm 566$ & $108350 \pm 14920$ & $114650 \pm 4031$ & $129200 \pm 1980$ \\
İ İstasyonu & $55450 \pm 1898$ & $115700 \pm 2546$ & $110200 \pm 11597$ & $112300 \pm 1697$ & $103100 \pm 17577$ \\
M İstasyonu & $53300 \pm 1004$ & $117050 \pm 4172$ & $111400 \pm 12445$ & $115500 \pm 2404$ & $135550 \pm 13081$ \\
K İstasyonu & $52350 \pm 1384$ & $116150 \pm 636$ & $107750 \pm 7707$ & $111200 \pm 3394$ & $130650 \pm 7425$ \\
\hline
\end{tabular}

Eser elementlerin konsantrasyonları ayda iki kere alınan numunelerin üç paralelli olarak analiz edilmesiyle 6 ölçümün ortalaması alınarak elde edilmiştir. Buna göre Tablo 3'de analiz sonucunda elde edilen bor konsantrasyonları verilmiştir.

Tablo 3. Analiz sonucunda elde edilen bor konsantrasyonları ve standart sapmaları

\begin{tabular}{|c|c|c|c|c|c|c|c|c|c|c|}
\hline \multirow{3}{*}{$\begin{array}{l}\text { İstasyonlar } \\
\text { P İstasyonu }\end{array}$} & \multicolumn{10}{|c|}{ Konsantrasyon (ppm) } \\
\hline & \multicolumn{2}{|c|}{ Kasım } & \multicolumn{2}{|c|}{ Aralık } & \multicolumn{2}{|c|}{ Ocak } & \multicolumn{2}{|c|}{ Şubat } & \multicolumn{2}{|c|}{ Mart } \\
\hline & 7,0600 & $\pm 0,4796$ & 7,0060 & $\pm 0,0852$ & 6,7560 & $\pm 0,1002$ & 7,0120 & $\pm 0,0643$ & 6,3780 & $\pm 0,0495$ \\
\hline İ İstasyonu & 7,0580 & $\pm 0,0893$ & 6,7020 & $\pm 0,0689$ & 6,4740 & $\pm 0,0326$ & 6,2320 & $\pm 0,0332$ & 4,7290 & $\pm 0,0604$ \\
\hline M İstasyonu & 7,1940 & $\pm 0,0764$ & 7,2640 & $\pm 0,1175$ & 6,7540 & $\pm 0,0774$ & 6,6840 & $\pm 0,0727$ & 6,0040 & $\pm 0,0868$ \\
\hline K İstasyonu & 6,2300 & $\pm 0,1284$ & 6,7800 & $\pm 0,1001$ & 6,7860 & $\pm 0,1185$ & 5,9340 & $\pm 0,0547$ & 6,1460 & $\pm 0,1112$ \\
\hline
\end{tabular}


Tablo 3'te bütün istasyonlarda bor konsantrasyonunun genel olarak kasım ve aralık aylarında diğer aylara göre daha yüksek olduğu görülmektedir. Bor konsantrasyonunun aralık ayında M istasyonunda en yüksek, mart ayında İ istasyonunda ise en düşük olduğu görülmektedir.

Tablo 4'de analiz sonucunda elde edilen alüminyum konsantrasyonları verilmiştir.

Tablo 4. Analiz sonucunda elde edilen alüminyum konsantrasyonları ve standart sapmaları

\begin{tabular}{lccccccccccc}
\hline \multirow{2}{*}{ İstasyonlar } & \multicolumn{10}{c}{ Konsantrasyon (ppm) } \\
\cline { 2 - 12 } & \multicolumn{2}{c}{ Kasım } & \multicolumn{1}{c}{ Aralı } & \multicolumn{1}{c}{ Ocak } & \multicolumn{2}{c}{ Şubat } & \multicolumn{2}{c}{ Mart } \\
\hline P İstasyonu & 0,1477 & $\pm 0,0150$ & 0,1612 & $\pm 0,0021$ & 0,1313 & $\pm 0,1486$ & 0,1408 & $\pm 0,0007$ & 0,0878 & $\pm 0,0022$ \\
İ İstasyonu & 0,3132 & $\pm 0,0044$ & 0,1818 & $\pm 0,0017$ & 0,1802 & $\pm 0,0082$ & 0,9773 & $\pm 0,0089$ & 0,0561 & $\pm 0,0024$ \\
M İstasyonu & 0,0435 & $\pm 0,0015$ & 0,0481 & $\pm 0,0005$ & 0,4801 & $\pm 0,0013$ & 0,0695 & $\pm 0,0006$ & 0,0474 & $\pm 0,0017$ \\
K İstasyonu & 0,1284 & $\pm 0,0009$ & 0,7644 & $\pm 0,0053$ & 6,1474 & $\pm 0,0042$ & 2,9218 & $\pm 0,0395$ & 0,2826 & $\pm 0,0129$ \\
\hline
\end{tabular}

Tablo 4'de alüminyum konsantrasyonunun ocak ayında K istasyonunda en yüksek, şubat ayında $\mathrm{M}$ istasyonunda ise en düşük olduğu görülmektedir. Genel olarak bakıldığında bütün aylarda en yüksek alüminyum konsantrasyonlarının $\mathrm{K}$ istasyonunda olduğu görülmektedir. Bunun nedeninin ise evsel atık kaynaklı olabileceği düşünülmektedir.

Tablo 5'de analiz sonucunda elde edilen krom konsantrasyonları verilmiştir.

Tablo 5. Analiz sonucunda elde edilen krom konsantrasyonları ve standart sapmaları

\begin{tabular}{lcccccccccccc}
\hline İstasyonlar & \multicolumn{1}{c}{ Konsantrasyon (ppm) } \\
\cline { 2 - 13 } & \multicolumn{2}{c}{ Kasım } & \multicolumn{1}{c}{ Aralık } & \multicolumn{2}{c}{ Ocak } & \multicolumn{3}{c}{ Şubat } & & Mart \\
\hline P İstasyonu & 0,1928 & $\pm 0,0071$ & 0,1873 & $\pm 0,0041$ & 0,2020 & $\pm 0,0026$ & 0,1978 & $\pm 0,0026$ & 0,1778 & $\pm 0,0021$ \\
İ İstasyonu & 0,2066 & $\pm 0,0037$ & 0,2220 & $\pm 0,0013$ & 0,2033 & $\pm 0,0024$ & 0,3095 & $\pm 0,0046$ & 0,1589 & $\pm 0,0033$ \\
M İstasyonu & 0,1903 & $\pm 0,0025$ & 0,2033 & $\pm 0,0017$ & 0,2375 & $\pm 0,0027$ & 0,1840 & $\pm 0,0024$ & 0,1881 & $\pm 0,0035$ \\
K İstasyonu & 0,2192 & $\pm 0,0031$ & 0,2730 & $\pm 0,0037$ & 0,5778 & $\pm 0,0025$ & 0,5042 & $\pm 0,0017$ & 0,2162 & $\pm 0,0032$ \\
\hline
\end{tabular}

Tablo 5'de genel olarak bakıldığında bütün istasyonlarda en yüksek krom konsantrasyonlarının ocak ve şubat aylarında olduğu görülmektedir. Krom konsantrasyonunun K istasyonunda ocak ayında en yüksek, İ istasyonunda mart ayında ise en düşük olduğu tespit edilmiştir.

Tablo 6' da analiz sonucunda elde edilen demir konsantrasyonları verilmiştir.

Tablo 6. Analiz sonucunda elde edilen demir konsantrasyonları ve standart sapmaları

\begin{tabular}{lcccccccccccc}
\hline \multirow{2}{*}{ İstasyonlar } & \multicolumn{10}{c}{ Konsantrasyon (ppm) } \\
\cline { 2 - 13 } & \multicolumn{2}{c}{ Kasım } & \multicolumn{1}{c}{ Aralık } & \multicolumn{1}{c}{ Ocak } & \multicolumn{3}{c}{ Şubat } & & Mart \\
\hline P İstasyonu & 5,5036 & $\pm 0,1466$ & 5,4276 & $\pm 0,0981$ & 5,6096 & $\pm 0,0875$ & 5,7016 & $\pm 0,0966$ & 5,0156 & $\pm 0,0689$ \\
İ İstasyonu & 6,3656 & $\pm 0,0315$ & 5,8876 & $\pm 0,0871$ & 5,5216 & $\pm 0,0879$ & 8,3396 & $\pm 0,0289$ & 4,5756 & $\pm 0,0671$ \\
M İstasyonu & 5,4956 & $\pm 0,0799$ & 5,7716 & $\pm 0,0864$ & 6,4516 & $\pm 0,0670$ & 5,0716 & $\pm 0,0552$ & 5,0036 & $\pm 0,0757$ \\
K İstasyonu & 5,5636 & $\pm 0,0997$ & 7,3496 & $\pm 0,0859$ & 21,9416 & $\pm 0,2210$ & 16,0756 & $\pm 0,1522$ & 6,1716 & $\pm 0,0757$ \\
\hline
\end{tabular}


Tablo 6'da demir konsantrasyonunun K istasyonunda ocak ayında en yüksek, İ istasyonunda mart ayında ise en düşük olduğu görülmektedir. İ istasyonunda şubat ayında konsantrasyonun yüksek bulunmasının bu ayda fabrika kaynaklı deşarjların fazla olmasından kaynaklandığı düşünülmektedir. $\mathrm{K}$ istasyonunda ise diğer istasyonlara göre hemen hemen bütün aylarda demir konsantrasyonunun yüksek olduğu gözlenmektedir, bu sonucun ise yine evsel atık kaynaklı deşarjlara bağlı olduğu tahmin edilmektedir.

Tablo 7'de analiz sonucunda elde edilen nikel konsantrasyonları verilmiştir.

Tablo 7. Analiz sonucunda elde edilen nikel konsantrasyonları ve standart sapmaları

\begin{tabular}{|c|c|c|c|c|c|c|c|c|c|c|}
\hline \multirow{3}{*}{$\begin{array}{l}\text { İstasyonlar } \\
\text { P İstasyonu }\end{array}$} & \multicolumn{10}{|c|}{ Konsantrasyon (ppm) } \\
\hline & \multicolumn{2}{|c|}{ Kasım } & \multicolumn{2}{|c|}{ Aralık } & \multicolumn{2}{|c|}{ Ocak } & \multicolumn{2}{|c|}{ Şubat } & \multicolumn{2}{|c|}{ Mart } \\
\hline & 0,0157 & $\pm 0,0029$ & 0,0204 & $\pm 0,0005$ & 0,0157 & $\pm 0,0015$ & 0,0226 & $\pm 0,0004$ & 0,0162 & $\pm 0,0004$ \\
\hline İ İstasyonu & 0,0199 & $\pm 0,0004$ & 0,0162 & $\pm 0,0005$ & 0,0132 & $\pm 0,0008$ & 0,1419 & $\pm 0,0005$ & 0,0072 & $\pm 0,0002$ \\
\hline M İstasyonu & 0,0091 & $\pm 0,0001$ & 0,0101 & $\pm 0,0003$ & 0,0455 & $\pm 0,0002$ & 0,0108 & $\pm 0,0002$ & 0,0099 & $\pm 0,0002$ \\
\hline K İstasyonu & 0,0181 & $\pm 0,0003$ & 0,0913 & $\pm 0,0022$ & 0,7507 & $\pm 0,0006$ & 0,6217 & $\pm 0,0081$ & 0,0308 & $\pm 0,0006$ \\
\hline
\end{tabular}

Tablo 7'de nikel konsantrasyonunun ocak ayında K istasyonunda en yüksek, İ istasyonunda mart ayında ise en düşük olduğu görülmektedir. Tüm istasyonlara bakıldığında ise nikel konsantrasyonunun $\mathrm{K}$ istasyonunda ocak ve şubat aylarında çok yüksek olduğu gözlenmektedir.

Tablo 8'de analiz sonucunda elde edilen bakır konsantrasyonları verilmiştir.

Tablo 8. Analiz sonucunda elde edilen bakır konsantrasyonları ve standart sapmaları

\begin{tabular}{ccccccccccccc}
\hline \multirow{2}{*}{ İstasyonlar } & \multicolumn{10}{c}{ Konsantrasyon (ppm) } \\
\cline { 2 - 14 } & \multicolumn{2}{c}{ Kasım } & \multicolumn{1}{c}{ Aralık } & \multicolumn{1}{c}{ Ocak } & \multicolumn{1}{c}{ Şubat } & & Mart \\
\hline P İstasyonu & 0,4136 & $\pm 0,0067$ & 0,3754 & $\pm 0,0046$ & 0,3878 & $\pm 0,0025$ & 0,4166 & $\pm 0,0071$ & 0,3676 & $\pm 0,0037$ \\
İ İstasyonu & 0,4300 & $\pm 0,0042$ & 0,3980 & $\pm 0,0130$ & 0,3340 & $\pm 0,0086$ & 0,2952 & $\pm 0,0063$ & 0,1727 & $\pm 0,0042$ \\
M İstasyonu & 0,4294 & $\pm 0,0125$ & 0,4470 & $\pm 0,0109$ & 0,3307 & $\pm 0,0101$ & 0,4002 & $\pm 0,0068$ & 0,3474 & $\pm 0,0114$ \\
K İstasyonu & 0,4034 & $\pm 0,0058$ & 0,3879 & $\pm 0,0071$ & 0,3696 & $\pm 0,0050$ & 0,2822 & $\pm 0,0021$ & 0,2845 & $\pm 0,0068$ \\
\hline
\end{tabular}

Tablo 8'de bakır konsantrasyonunun aralık ayında M istasyonunda en yüksek, mart ayında İ istasyonunda ise en düşük olduğu görülmektedir. Bütün istasyonlarda bakır konsantrasyonun kasım ayından mart ayına doğru genel olarak azaldığı görülmektedir.

Tablo 9'da analiz sonucunda elde edilen arsenik konsantrasyonları verilmiştir. 
Tablo 9. Analiz sonucunda elde edilen arsenik konsantrasyonları ve standart sapmaları

\begin{tabular}{|c|c|c|c|c|c|c|c|c|c|c|}
\hline \multirow{3}{*}{$\begin{array}{l}\text { İstasyonlar } \\
\text { P İstasyonu }\end{array}$} & \multicolumn{10}{|c|}{ Konsantrasyon (ppm) } \\
\hline & \multicolumn{2}{|c|}{ Kasım } & \multicolumn{2}{|c|}{ Aralık } & \multicolumn{2}{|c|}{ Ocak } & \multicolumn{2}{|c|}{ Şubat } & \multicolumn{2}{|c|}{ Mart } \\
\hline & 0,0546 & $\pm 0,0019$ & 0,0532 & $\pm 0,0011$ & 0,0546 & $\pm 0,0012$ & 0,0549 & $\pm 0,0013$ & 0,0468 & $\pm 0,0011$ \\
\hline İ İstasyonu & 0,0559 & $\pm 0,0009$ & 0,0578 & $\pm 0,0015$ & 0,0534 & $\pm 0,0012$ & 0,0578 & $\pm 0,0007$ & 0,0368 & $\pm 0,0004$ \\
\hline M İstasyonu & 0,0557 & $\pm 0,0016$ & 0,0584 & $\pm 0,0016$ & 0,0583 & $\pm 0,0004$ & 0,0537 & $\pm 0,0009$ & 0,0509 & $\pm 0,0011$ \\
\hline K İstasyonu & 0,0521 & $\pm 0,0016$ & 0,0615 & $\pm 0,0009$ & 0,0748 & $\pm 0,0007$ & 0,0640 & $\pm 0,0007$ & 0,0533 & $\pm 0,0018$ \\
\hline
\end{tabular}

Tablo 9'da arsenik konsantrasyonunun ocak ayında K istasyonunda en yüksek, mart ayında İ istasyonunda ise en düşük olduğu görülmektedir. Bütün istasyonlar incelendiğinde arsenik konsantrasyonunun genel olarak en yüksek olduğu istasyonun $\mathrm{K}$ istasyonu olduğu görülmektedir.

Tablo 10'da analiz sonucunda elde edilen selenyum konsantrasyonları verilmiştir.

Tablo 10. Analiz sonucunda elde edilen selenyum konsantrasyonları ve standart sapmaları

\begin{tabular}{|c|c|c|c|c|c|c|c|c|c|c|}
\hline \multirow{3}{*}{$\begin{array}{l}\text { İstasyonlar } \\
\text { P İstasyonu }\end{array}$} & \multicolumn{10}{|c|}{ Konsantrasyon (ppm) } \\
\hline & \multicolumn{2}{|c|}{ Kasım } & \multicolumn{2}{|c|}{ Aralık } & \multicolumn{2}{|c|}{ Ocak } & \multicolumn{2}{|c|}{ Şubat } & \multicolumn{2}{|c|}{ Mart } \\
\hline & 0,2909 & $\pm 0,0265$ & 0,2865 & $\pm 0,0088$ & 0,2833 & $\pm 0,0032$ & 0,2877 & $\pm 0,0069$ & 0,2608 & $\pm 0,0076$ \\
\hline İ İstasyonu & 0,2939 & $\pm 0,0046$ & 0,2806 & $\pm 0,0098$ & 0,2718 & $\pm 0,0072$ & 0,2697 & $\pm 0,0114$ & 0,1973 & $\pm 0,0072$ \\
\hline M İstasyonu & 0,2956 & $\pm 0,0077$ & 0,3007 & $\pm 0,0079$ & 0,2813 & $\pm 0,0125$ & 0,2829 & $\pm 0,0126$ & 0,2535 & $\pm 0,0049$ \\
\hline K İstasyonu & 0,2618 & $\pm 0,0071$ & 0,2825 & $\pm 0,0093$ & 0,2882 & $\pm 0,0133$ & 0,2595 & $\pm 0,0057$ & 0,2634 & $\pm 0,0110$ \\
\hline
\end{tabular}

Tablo 10'da selenyum konsantrasyonunun $\mathrm{M}$ istasyonunda aralık ayında en yüksek, İ istasyonunda mart ayında ise en düşük olduğu görülmektedir. Bütün istasyonlar incelendiğinde genel olarak en yüksek selenyum konsantrasyonunun M istasyonunda olduğu görülmektedir.

Tablo 11'de 40 numunenin üç paralelli olarak analiz edilmesiyle belirlenen eser element konsantrasyonlarının ortalamaları ve denizlerdeki kabul edilebilir değerleri görülmektedir.

Tablo 11. Çalışmada incelenen eser element konsantrasyonlarının ortalamaları ve denizlerdeki kabul edilebilir değerleri (Anonim, 2010)

\begin{tabular}{ccl}
\hline Eser Element & Bu Çalışmadaki Konsantrasyon (ppm) & $\begin{array}{l}\text { Denizlerdeki } \\
\text { Edilebilir Değer (ppm) }\end{array}$ \\
\hline $\mathrm{B}$ & $6,559 \pm 0,606$ & 3,0 \\
$\mathrm{Al}$ & $0,666 \pm 0,156$ & 0,07 \\
$\mathrm{Cr}$ & $0,243 \pm 0,015$ & 0,1 \\
$\mathrm{Fe}$ & $7,142 \pm 0,443$ & 0,7 \\
$\mathrm{Ni}$ & $0,094 \pm 0,009$ & 0,3 \\
$\mathrm{Cu}$ & $0,364 \pm 0,034$ & 0,01 \\
$\mathrm{As}$ & $0,055 \pm 0,005$ & 0,1 \\
$\mathrm{Se}$ & $0,275 \pm 0,047$ & 0,05 \\
\hline
\end{tabular}


Daha önce İskenderun Körfezi’nde yapılan çalışmada Cd: 0,0550, Fe: 0,2995, Cu: 0,0652, Pb: 0,6173, Zn: 0,0709, Co: 0,2589, Cr: 0,1689, Al: 0,1875, Mn: 0,1079 ve Ni: 0,2769 ppm olarak bulunmuştur (Türkmen, A., 2003; Türkmen ve Aras, 2011).

\section{Sonuçlar ve Öneriler}

$\mathrm{Bu}$ çalışmada beş ay boyunca İskenderun Körfezi'nde kirlilik araştırması yapılmıştır. İskenderun Körfezi'nin farklı bölgelerinden alınan deniz suyu örneklerinde $\mathrm{pH}$ ve iletkenlik değerleri ile eser element konsantrasyonları belirlenmiştir. Tüm istasyonlarda elde edilen eser element konsantrasyonları sürekli olarak müsaade edilebilir seviyenin üzerinde bulunduğu için bu bölgelerde sürekli bir kirletici kaynağının bulunduğu düşünülmektedir. Aynı zamanda birçok canlının yaşam alanı olan deniz suyunun kirlenmesi; deniz canlılarının ve dolaylı yoldan da insanların zarar görmesine sebep olmaktadır.

Numunelerin toplandığı ayların ve istasyonların fark gözetmeksizin deniz suyundaki ortalama eser element konsantrasyonlar1; B: 6,559; Al: 0,666; Cr: 0,243, Fe: 7,142; Ni: 0,094; Cu: 0,364; As: 0,055 ve Se: 0,275 ppm olarak bulunmuştur. Tarım ve Köy İşleri Bakanlığının (7/1/2010-27455) sayılı su ürünleri yönetmeliğine göre bu çalışmada araştırılan eser elementlerin denizlerde ve iç sularda müsaade edilebilir düzeyleri ile kıyaslandığında belirlenen $\mathrm{B}, \mathrm{Al}, \mathrm{Cr}, \mathrm{Fe}, \mathrm{Cu}, \mathrm{Se}$ konsantrasyonlarının yüksek, Ni ve As elementlerinin konsantrasyonlarının ise düşük olduğu görülmektedir. Bu sonuçlara bakarak İskenderun Körfezi’nin B, Al, Cr, Fe, Cu, Se yönünden kirliliğe maruz kaldığı söylenebilir. Bunun yanı sıra diğer elementlerin konsantrasyonları bazı aylarda farklılıklar göstermiştir. Bu durumun bölgede arıtılmış ve arıtılmamış suların deşarjından, liman içi ve insan kaynaklı faaliyetlerin mevsimsel olarak farklılıklar oluşturmasından kaynaklandığ düşünülmektedir. P ve İ istasyonlarında endüstriyel faaliyetler fazla iken $\mathrm{K}$ ve $\mathrm{M}$ istasyonlarında ise nüfus yoğunluğu fazladır. Özellikle $\mathrm{K}$ istasyonundan alınan numunelerde $\mathrm{Ni}, \mathrm{Fe}, \mathrm{Cr}$ ve $\mathrm{Al}$ konsantrasyonlarının diğer istasyonlara göre belirgin bir şekilde yüksek olduğu gözlenmiştir. Buna göre insan kaynaklı faaliyetlerin en az endüstriyel faaliyetler kadar deniz suyunda kirliliğe sebep olduğu belirlenmiştir. Bu durumun nedeninin arıtılmamış suların deşarjı ve körfezi etkisi altına alan hava akımı olduğu tahmin edilmektedir.

Bölgede bulunan birçok sanayi kuruluşunun ve evsel atık sularının kontrolsüz bir şekilde İskenderun Körfezi'ne kontrol dışı ya da kuralsız deşarjlara sebep olduğu düşünülmektedir. Bu gibi kontrol dışı ve ekosistemi tehdit eden durumların önlenmesi, liman faaliyetlerinin kontrollü bir şekilde gerçekleşmesi ve bu konuda bölgede uzun süreli, kapsamlı çalışmaların sürdürülmesi sonucunda İskenderun Körfezi ve çevresindeki kirlilik kontrol altına alınabilir. 


\section{Teșekkür}

$\mathrm{Bu}$ çalışma, Mustafa Kemal Üniversitesi Bilimsel Araştırma Projeleri Koordinatörlüğü tarafından 13183 proje ile desteklenmiştir.

\section{Kaynaklar}

Anonim, (2004). Antalya Kent Konseyi Raporları. www.antalyakentkonseyi.org.tr/raporlar_cevre_grubu.html Erişim Tarihi: (1 Mart 2016).

Anonim, (2010). www.mevzuat.gov.tr/MevzuatMetin/yonetmelik/7.5.4988\%20ekler.doc. , (Erişim tarihi: 1 Mart 2016).

Beğenirbeş, G. C A. S., (2002). Porsuk Çayı (Kütahya Bölümü) 'ndaki Tatlısu Midyesi (Unio sp.) 'nde bazı ăgır metallerin araştırılması. Yüksek Lisans Tezi, Anadolu Üniversitesi, Fen Bilimleri Enstitüsü, Eskişehir.

Buckley, D. E., Smith, J. N. and Winters, G. V., (1995). Accumualation of contaminant metals in marine sediments of Halifax harbour, Nova Scotia: environmental factors and historical trends. Appl. Geochem., 10, 175-195.

Censi P.,Spoto S. E., Saiano F., Sprovieri M., Mazzola S., Nardone G., Di Geronimo S.I., Punturo R. and Ottonello D., (2006). Heavy metals in coastal water systems. A case study fromt the Northwestern Gulf of Thailand. Chemosphere, 64 (7), 1167-1176.

Cubadda, F., Conti, M. E. and Campanella, L. (2001). Size-dependent concentrations of trace metals in four Mediterranean gastropods. Chemosphere, 45, 561-569.

Ergül H. A., Varol T. ve Ay Ü., (2013). Investigation of heavy metal pollutants at various depths in the Gulf of Izmit. Marine Pollution Bulletin, 73 (1), 389-393.

Hamed M.A. and Emara A.M., 2006. Marine Molluscs as Bio monitörs for Heavy Metal Levels in theGulf of Suez, Red Sea. Journal of Marine Systems, 60 (3): 220-234.

Karadere, H., (1997). Atatürk Baraj Gölü"nde su, sediment ve balık türlerinde ağır metal birikiminin araştırılması. Yüksek Lisans Tezi, Dicle Üniversitesi, Fen Bilimleri Enstitüsü, Diyarbakır.

Lijklema, L., Koelmans, A.A., and Portielje, R., (1993). Water Quality Impacts of Sediment pollution andt he Role of Early Diagnosis. Water Science and Technology, 28, 1-16.

Pertsemli E. and Voutsa D., (2007). Distribution of heavy metals in lakes Doiraniand Kerkini, Northern Greece. Journal of Hazardous Materials, 148 (3), 529-537.

Topçuoğlu, S., (2005). Deniz Kirliliği, İstanbul: Tüdav Yayınları.

Türkmen, A., (2003). İskenderun Körfezi'nde deniz suyu, askıdaki katı madde, sediment ve dikenli taş istiridyesinde (Spondylus Spinosus Schreibers, 1793) oluşan ağır metal birikimi üzerine araştırma. Atatürk Üniversitesi, Fen Bilimleri Enstitüsü, Doktora Tezi,s 152, Erzurum.

Türkmen A. ve Aras, S. (2011). İskenderun Körfezi'nde deniz suyu ve sedimentte oluşan ağır metal birikiminin incelenmesi. Karadeniz Fen Bilimleri Dergisi, 1-23.

Uzunoğlu, O.,1999. Gediz Nehri’nden alınan su ve sediment örneklerinde bazl ăgır metal konsantrasyonlarının belirlenmesi. Yüksek Lisans Tezi, Celal Bayar Üniversitesi, Fen Bilimleri Enstitüsü, Manisa. 